\begin{tabular}{ll|l}
\cline { 2 - 3 } & \multicolumn{2}{l}{ Intervent Neurol 2013;2:97-104 } \\
\cline { 2 - 3 } & $\begin{array}{l}\text { DOI: 10.1159/000356087 2014 S. Karger AG, Basel } \\
\text { Published online: March 20, } 2014\end{array}$ & $\begin{array}{l}\text { 1664-9737/14/0023-0097\$39.50/0 } \\
\text { www.karger.com/ine }\end{array}$ \\
\hline
\end{tabular}

\title{
Future Directions for Intra-Arterial Therapy for Acute Ischaemic Stroke: Is There Life after Three Negative Randomized Controlled Studies?
}

\author{
Julian Maingard ${ }^{a} \quad$ Bernard Yan $^{a}, b$ \\ a Melbourne Brain Centre and b Neurointervention Service, Department of Radiology, \\ Royal Melbourne Hospital, Melbourne, Vic., Australia
}

\section{Key Words}

Acute ischaemic stroke $\cdot$ Intravenous thrombolysis · Intra-arterial therapy $\cdot$ Recanalization success

\begin{abstract}
Background: The three randomised controlled trials, Interventional Management of Stroke III (IMS3), Mechanical Retrieval and Revascularization of Stroke Clots Using Embolectomy (MR RESCUE) and Synthesis Expanasion: A Randomized Controlled Trial on Intra-Arterial Versus Intravenous Thrombolysis in Acute Ischaemic Stroke (SYNTHESIS EXP) showed no significant difference in clinical outcomes comparing intra-arterial (IA) therapy with intravenous thrombolysis. This article will explore the reasons for failure to show superiority of IA therapy. Summary: There are many reasons for the disappointing results of the three randomised controlled trials. Opposing views on IA therapy exist. Critics argue that only a small percentage of patients will be eligible for IA therapy and that it will never be cost-effective. Additionally, current trials have failed to address superior recanalization rates of new generation devices and lack of patient selection by advanced imaging. Time-to-treatment is longer in these randomised controlled trials and stroke outcomes were worse than anticipated. The current randomised controlled trials also took long periods to complete. There is emerging evidence that general anesthetic negatively influences outcome. Next generation trials will attempt to address these issues. Key Messages: There are disparate explanations for the disappointing results from the three IA therapy randomized controlled studies. Poor recanalisation rates with first generation endovascular devices, lack of advanced neuroimaging to aid in patient selection, lack of data surrounding the use of general anaesthesia, and prolonged time-to-treatment are potential contributors to negative results. The new generation of trials has the potential of addressing these pressing issues.

(C) 2014 S. Karger AG, Basel
\end{abstract}




\section{Introduction}

Intravenous thrombolysis (IV tPA) is an effective treatment for acute ischaemic stroke [1]. However, up to $64 \%$ of patients have at least one contraindication for treatment with IV tPA, leading to lost treatment opportunities [2]. In addition, recanalization success after IV TPA is dependent on the location of the occlusion [3]. Internal carotid artery terminus occlusions fail to recanalize in more than $90 \%$ of cases after IV tPA [3]. Intra-arterial (IA) therapy, encompassing a range of modalities including IA thrombolysis and mechanical clot retrieval, is an emerging treatment alternative with significantly higher recanalization rates [4]. Its use in acute ischaemic stroke, however, remains a topic of debate. The three randomized controlled trials (RCTs), Interventional Management of Stroke III (IMS3), Mechanical Retrieval and Revascularization of Stroke Clots Using Embolectomy (MR RESCUE) and Synthesis Expansion: a Randomized Controlled Trial on Intra-Arterial versus Intravenous Thrombolysis in Acute Ischaemic Stroke (SYNTHESISEXP), showed no significant difference in clinical outcomes comparing IA therapy with IV tPA [5-7]. This article will explore the reasons for failure to show superiority of IA therapy and, in addition, outline the next generation of RCTs of IA therapy.

\section{Brief Overview of the Three IA Therapy RCTs}

IMS3 was an international phase 3 open-label RCT that included 656 patients presenting with acute ischaemic stroke within $3 \mathrm{~h}$ who were randomized into treatment with IV tPA or IV tPA followed by IA therapy. The primary outcome was modified Rankin Scale (mRS) at 90 days. The study aimed to include 900 patients but was stopped early due to futility. The authors concluded that there was no statistically significant difference in outcomes between those treated with combination IV tPA and IA therapy and IV tPA alone (40.8 vs. $38.7 \%$, respectively, $\mathrm{p}=0.25$ ) [5].

The SYNTHESIS trial included 363 patients presenting within $4.5 \mathrm{~h}$ of symptom onset. It enrolled patients equally into two treatment arms using either IV tPA or a range of IA therapies. The primary outcome was mRS at 90 days. There was no significant difference in outcomes between the two groups (IV 34.5\%, IA 30.4\%, OR 0.71, p = 0.16) [6].

Finally, MR RESCUE, a phase $2 \mathrm{~b}$ open-label and multicentre RCT enrolled a total of 118 patients. The primary outcome was mean $\mathrm{mRS}$ at 90 days. It included patients presenting within $8 \mathrm{~h}$ of symptom onset and enrolled patients to receive either standard care (IV tPA) or IA therapy through mechanical embolectomy. There was no significant difference between treatment with embolectomy and standard care (mean mRS 3.9 vs. 3.9, respectively, $\mathrm{p}=$ 0.99) [7].

\section{Opposing Views on IA Therapy}

In the following, we will summarize and appraise the validity of the different opposing views in the debate surrounding IA therapy. These views are broadly categorized into negative and affirmative views on IA therapy.

\section{The Negative Views}

'Only a Small Percentage of Patients Will Be Eligible for IA Therapy'

There is a view that only a small percentage of patients are eligible for IA therapy. This view was supported by the low percentage of patients recruited into the early RCTs. In the Prolyse in Acute Cerebral Thromboembolism II (PROACT II) trial, 12,323 patients with acute 
ischaemic stroke were screened for potential enrolment and treatment with IA recombinant prourokinase [8]. Only $4 \%$ of patients $(n=474)$ underwent diagnostic angiography of whom 180 were randomized [8]. This represents an approximately 200:3 ratio of screened-torandomized patients. However, in IMS3 approximately 5,000 patients were screened and 656 randomized [5]. The ratio of screened-to-randomized patients is approximately 9:1, a significant improvement since PROACT II. This demonstrates that as our understanding of IA intervention and the diversity of methods available increases so does the number of patients who are eligible. Recent estimates indicate that between 27,000 and 96,000 (4-14\%) patients will be eligible for IA therapy annually in the USA [9].

The relative unavailability of neurointerventionists is another criticism that has been raised, particularly during out-of-hours periods. Neurointerventional training is in fact becoming increasingly more common. There are an estimated 800 neurointerventionists in the USA with approximately 40 neurointerventional fellows graduating every year. The estimates are that in 5-10 years' time this number may reach between 1,000 and 1,200 [9]. Fiorella et al. [10] further estimate that as many as 80-100 neurointerventional fellows are graduating every year.

In 1990 , only $36.2 \%$ of patients with ischaemic stroke and $45.7 \%$ with stroke-in-evolution presented to hospital within $24 \mathrm{~h} \mathrm{[11].} \mathrm{An} \mathrm{increasing} \mathrm{proportion} \mathrm{of} \mathrm{patients} \mathrm{are} \mathrm{now}$ arriving at hospital within $4.5 \mathrm{~h}$ with up to $28.3 \%$ arriving in less than $60 \mathrm{~min}$ and $60 \%$ arriving within $3 \mathrm{~h}$. [12]. In our centre alone the mean onset-to-door time was 73 min in 2012. Significantly, door-to-needle times have reduced to less than 30 min [13]. In Helsinki, in 2011, $94 \%$ of patients achieved a door-to-needle time (in IV tPA) of 20 min [14]. The implication is that more patients are becoming eligible for not only IV tPA but IA therapy also.

\section{'IA Therapy Will Never Be Cost-Effective'}

The cost-effectiveness of IA therapy is another important consideration in the generalizability of IA therapy. Of interest, critics of IV tPA were pessimistic of cost-benefit ratio, declaring it 'expensive, potentially harmful, and possibly only marginally effective' [15]. Some even called for its use to be withheld [16]. IA thrombolysis is associated with an increase in acute care costs of USD 15,000 per patient [17]. However, while IV tPA is potentially harmful and not always effective it is a cost-effective treatment, allowing for an incremental costeffectiveness ratio ranging from USD 1,478 to 21,978 for each 1.0 quality-adjusted life year (QALY) $[18,19]$. The average procedural costassociated with stent retriever devices (including the Solitaire device) is approximately USD $16,022(p=0.0002)$ [20]. Another US study showed the mean cost of IA therapy was USD 24,154 and USD 6,749 for standard medical therapy. It demonstrated 2.37 QALYs gained in the mechanical thrombectomy group compared to 1.83 QALYs in standard medical therapy. This equated to an incremental cost-effectiveness ratio of USD 12,120 for each 1.0 QALY gained in the IA therapy group [21]. IA therapy has therefore been shown to be cost-effective. To ensure cost-effectiveness additional acute care costs need to be offset by a reduction in the length of hospital stay, associated long-term morbidity and subsequently overall total cost of care. The hope is that in the future the high cost of materials and instrumentation may be reduced as more companies attempt to develop superior recanalization devices. The question of cost-effectiveness is being further addressed in the Trial and Cost Effectiveness Evaluation of Intra-Arterial Thrombectomy in Acute Ischemic Stroke (THRACE) [22].

\section{The Affirmative Views}

'Superior Recanalization Rates of New Generation Devices'

Currently there are a number of devices available for the interventional management of acute ischaemic stroke. These include IA thrombolysis, the Merci retriever, the Penumbra 
Maingard et al.: Future Directions for Intra-Arterial Therapy for Acute Ischaemic Stroke: Is There Life after Three Negative Randomized Controlled Studies?

system, and stent retrievers such as the Solitaire device. The Solitaire device, which has been cleared by the FDA for use in 2012, is probably the most effective endovascular device currently in use. The SWIFT trial randomized 113 patients comparing the Solitaire FR stent retriever to the MERCI clot retrieval device, demonstrating successful recanalization without symptomatic intracerebral haemorrhage in $80.4 \%$ compared to $57.4 \%$, respectively $\left(\mathrm{p}_{\text {superiority }}=0.0002\right)$. Good clinical outcomes were higher in the Solitaire FR group (58.2 vs. $33.3 \%, \mathrm{p}_{\text {superiority }}=0.017$ ) [23]. A recent meta-analysis showed that retrievable stents (exclusively Solitaire except in one study) had the highest rate of recanalization and good functional outcomes and the lowest mortality [24]. It is now widely used by many neurointerventional centres. Despite this data the Solitaire device was only used in 18 of 165 patients in SYNTHESIS [6], in 5 of 334 patients in IMS3 [25] and in none of the patients in the MR RESCUE trial [7]. IMS3, SYNTHESIS and MR RESCUE, therefore, predominantly used outdated technology with lower recanalization rates. Futile recanalization is associated with poor clinical outcomes.

'RCTs Failed because of Lack of Patient Selection by Advanced Imaging'

As IA therapy has been increasingly utilized the need for appropriate patient selection has become more important. Standard neuroimaging protocols exist in most neurointerventional centres that allow for rapid and accurate identification of those patients likely to benefit from early IA therapy. This includes non-contrast computed tomography (CT), CT angiography (CTA) and CT perfusion. Appropriate imaging criteria have previously been used to select patients most likely to benefit from IV tPA [26]. The same approach must be used in IA intervention. An identifiable occlusion, penumbral pattern and clot characteristics are key parameters that should be considered.

CTA allows for accurate non-invasive identification of occlusion location. Current IA therapy RCTs did not utilize CTA in the assessment of all patients. Of note, in IMS3 CTA was not utilized in 350 randomized patients. Furthermore, in those who did have a CTA at baseline, 24 had no identifiable occlusion, 21 of whom were enrolled into the IA therapy treatment arm [25]. In the SYNTHESIS trial some patients were enrolled into the IA therapy treatment arm in which there was no identifiable arterial occlusion. IA tPA was instead delivered into parent arteries of areas presumed to be affected. The authors stated that CTA was not an essential tool for their study [27]. A large proportion of patients were therefore treated with IA therapy without confirmation of large artery occlusion prior to intervention.

Perfusion-diffusion mismatch has been shown to be a powerful tool in selecting patients likely to benefit from reperfusion therapy. The DEFUSE I and II studies evaluated penumbra imaging and its correlation to good clinical outcome in IV tPA (OR 70, p =0.001) and IA therapy (OR 8.8 with mismatch and 0.2 without), respectively $[28,29]$. CT perfusion, which identifies the ischaemic penumbra, was underutilized in the current IA therapy RCTs [5-7].

The median predicted infarct core across all patients in MR RESCUE was $60.2 \mathrm{ml}$ [7]. Functional outcomes were higher in the DEFUSE studies. Diffusion-weighted imaging-based median infarct core volumes in DEFUSE I and II were 8.5 and $13 \mathrm{ml}$ (mismatch group), respectively $[28,29]$. Gasparotti et al. [30] have demonstrated that infarct core is a strong predictor of clinical outcome. They also demonstrated that an increment of $13.2 \mathrm{ml}$ in infarct core correlated with an increase in mRS of 0.96 (95\% CI 0.17-1.75, $p=0.01)$. This may explain poor functional outcomes.

'Time-to-Treatment Is Longer in These RCTs'

Arterial recanalization is known to correlate well with good clinical outcome [4]. In addition it is well established that time-to-treatment in IV tPA is of maximum benefit the earlier treatment is initiated. Results of the pooled analysis of ECASS, ATLANTIS, NINDS and EPITHET trials show that the number-needed-to-treat for a good outcome (mRS 0-1) in IV tPA 
Maingard et al.: Future Directions for Intra-Arterial Therapy for Acute Ischaemic Stroke: Is There Life after Three Negative Randomized Controlled Studies?

initiated in the first $90 \mathrm{~min}$ is 4.5. This increases to $9.0 \mathrm{in} 91-180 \mathrm{~min}$ and to 14.1 in 181-270 $\mathrm{min}$; the number-needed-to-treat balloons to 21.4 in the time window of 271-360 $\mathrm{min}$ [1]. Similarly, earlier intervention in IA therapy improves recanalization rates and thus clinical outcomes [31]. Given these results, important treatment variables that clinicians need to consider are door-to-needle, door-to-groin and CT-to-groin times. Current studies have included patients up to $8 \mathrm{~h}$ from symptom onset but have failed to adequately record these variables, making it relatively difficult to assess how much of treatment delay is attributable to inpatient versus pre-hospital management. Rather, onset-to-groin and onset-to-IA therapy times are quoted. Onset-to-groin time was $208 \pm 46.7 \mathrm{~min}$ in the IMS3 trial and $381 \pm 74 \mathrm{~min}$ in MR RESCUE. Onset-to-IA therapy was $249.4 \pm 50.6 \mathrm{~min}$ in IMS3 and $225 \mathrm{~min}$ in SYNTHESIS [5-7]. Onset-to-needle times for IV tPA are only quoted in IMS3 and are comparable to previous trials $[1,5]$. For example, mean CT-to-groin time in MR RESCUE was $124 \pm 56$ min, representing a significant delay from identification of stroke patients to institution of IA therapy [7].

The drip-and-ship treatment paradigm involves commencing IV tPA in stroke patients in smaller community hospitals prior to transfer to larger tertiary stroke centres to undergo IA therapy [32]. While this has been shown to be a safe treatment strategy, it may worsen onsetto-treatment times [33]. IMS3 did not include data on how many patients were treated using this method. MR RESCUE and SYNTHESIS did not make mention of this at all [5-7]. Potential for selection bias may also exist in choosing to randomize patients treated in this manner [34]. Both delayed treatment times and selection bias have the potential to impact on functional outcomes in the intervention arms of these studies.

'Stroke Outcomes Were Worse than Anticipated in the RCTs'

In IMS3 a good functional outcome (mRS 0-2) at 90 days was achieved in $40.8 \%$ of IA patients and $38.7 \%$ of IV tPA patients. This fell in those achieving mRS $0-1$ to $29.4 \%$ of IA patients and $27.1 \%$ of IV tPA patients [5-7]. SYNTHESIS defined mRS $0-1$ as a good functional outcome. Only $30.4 \%$ of IA patients and $34.5 \%$ of IV tPA patients achieved this result [6]. These results were significantly lower than those in the pooled analysis of IV tPA trials [1]. Furthermore, in MR RESCUE a good outcome (mRS 0-2) was only achieved in $21 \%$ of IA-treated patients and $26 \%$ of those undergoing standard care (penumbral group). In this study, the proportion of patients with mRS 0-1 at 90 days in the IA- and IV tPA-treated patients from the penumbral group was 9 and 15\%, respectively [7]. This is significantly lower than outcomes of IA-treated patients in IMS3, SYNTHESIS and IV tPA trials $[1,5,6]$.

The rates of recanalization in IA-treated patients in MR RESCUE were 67 and $77 \%$ in the penumbral and non-penumbral groups, respectively [7]. This is significantly lower than in other studies and may explain why such a small proportion of patients achieved a good functional outcome.

\section{'RCTs Took Long Periods to Complete'}

Despite the randomization of patients, selection bias may still exist in choosing when and which patients to enrol in the study. MR RESCUE took place between 2004 and 2011 and during this 7-year period only 127 patients were enrolled [7]. In a 6-year time period IMS3 enrolled 656 patients and in a 4-year period SYNTHESIS enrolled 362 patients [5, 6]. There is no readily available data on when the first patient was randomized into MR RESCUE. Given that this was an open-label trial, such a significant delay to trial completion may represent a significant amount of selection bias by the investigators when choosing which patients to enrol in the trial. Additionally, patients in MR RESCUE who were treated with IV tPA who did not successfully recanalize with persistent occlusion on CTA or MRA were eligible for further treatment with IA therapy [7]. No data were available on how many patients were enrolled in the treatment arm in this way. Given what we know about superior recanalization in IA 
therapy this has the potential to negate poorer outcomes than would otherwise have been expected in the IV tPA-treated patients [4].

'There Is Emerging Evidence that General Anaesthetic Negatively Influences Outcome'

Lastly, the use of general anaesthetic (GA) or conscious sedation is an important discussion point. Davis et al. [35] showed that in patients receiving GA for IA treatment $15 \%$ had a good clinical outcome (mRS 0-2). This is compared to $60 \%$ of those receiving local anaesthesia or conscious sedation after adjustment for stroke severity. The authors attributed this to complications related to relative systolic hypotension rather than a delay in therapy. John et al. [36] concluded that poorer outcomes have been observed in patients undergoing IA therapy under GA. Difficulties using GA in a time-critical situation include the availability of anaesthetic staff and, in most cases, time to anaesthetic induction. Current IA therapy trials have failed to address these issues. In the SYNTHESIS trial 22 patients underwent GA but no data were supplied in the IMS3 or MR RESCUE trials [5-7]. The IMS3 authors did mention that conscious sedation was preferred but no specific protocol existed [25].

\section{Next Generation Trials}

The next generation of RCTs are being undertaken, which are attempting to address some of the pressing issues surrounding IA therapy listed above. These trials include EXTEND-IA, SWIFT PRIME, THERAPY, REVASCAT and MR CLEAN.

EXTEND IA (Extending the Time for Thrombolysis in Emergency Neurological Deficits Intra-Arterial) is a prospective, randomized, open-label, blinded end-point (PROBE) trial. Between 2012 and 2014 the trial will attempt to enrol 100 patients with 1:1 randomization to either treatment with IV tPA and IA clot retrieval with the Solitaire device or IV tPA alone. It will use newer generation devices and more advanced neuroimaging selection criteria through CTA or MRA to identify an arterial occlusion amenable to treatment and CT or MRI to appropriately identify patients with an ischaemic penumbra prior to randomization. The primary outcomes are reperfusion at $24 \mathrm{~h}$ on perfusion imaging and NIHSS at 3 days. There are a number of secondary outcomes including mRS at 3 months [37].

SWIFT PRIME (Solitaire FR with the Intention for Thrombectomy as Primary Endovascular Treatment for Acute Ischemic Stroke) is essentially a follow-on from the original SWIFT trial. Between 2012 and 2018 the authors will attempt to enrol 833 patients with a primary outcome of mRS at 90 days. It is a randomized open-label trial that will attempt to determine if those with acute ischaemic stroke due to large vessel occlusion will benefit from combined IV tPA and IA therapy with the Solitaire FR device versus IV tPA alone. Patients will need to have a demonstrable occlusion (internal carotid artery/M1/carotid terminus) on CT or MRI with a thrombolysis in cerebral infarction score of $0-1$ prior to randomization. As with EXTEND IA this trial attempts to address the issues of inadequate patient selection and inferior endovascular device use in already published trials [38].

THERAPY (the THERAPY Trial: the Randomized, Concurrent Controlled Trial to Assess the Penumbra System's Safety and Effectiveness in the Treatment of Acute Stroke) will test the Penumbra system in addition to IV tPA versus IV tPA alone in 692 patients enrolled from 2012 to 2016. These patients will need to have evidence of anterior circulation large vessel occlusion with a clot length greater than $8 \mathrm{~mm}$ prior to randomization. This will address recanalization in those more likely to fail IV tPA. Primary end points are mRS at 90 days and incidence of all adverse events [39].

REVASCAT (Randomized Trial of Revascularization with Solitaire FR Device versus Best Medical Therapy in the Treatment of Acute Stroke due to Anterior Circulation Large Vessel 
Occlusion Presenting within 8 Hours of Symptom Onset) will evaluate the Solitaire FR device against medical management using the PROBE design in achieving favourable clinical outcomes. A total of 690 patients will be enrolled from 2012 to 2015 and will be required to have a thrombolysis in cerebral infarction score of $0-1$ on CTA or MRA. Primary outcome is mRS distribution (using shift analysis). Secondary outcomes are mortality at 90 days, symptomatic intracerebral haemorrhage, NIHSS at $24 \mathrm{~h}$, infarct volume and vessel recanalization [40].

Finally, MR CLEAN (Multicenter Randomized Clinical Trial of Endovascular Treatment for Acute Ischemic Stroke in the Netherlands) is another PROBE-designed trial investigating IA therapies against regular medical treatment. Arterial occlusion will need to be demonstrated using CTA, MRA, DSA or transcranial Doppler in the anterior circulation. Between 2010 and 2015, a total of 500 patients will be enrolled. Primary outcome is mRS at 3 months [41].

\section{Conclusion}

There are disparate explanations for the disappointing results from the three IA therapy RCTs. Poor recanalization rates with first generation endovascular devices, lack of advanced neuroimaging to aid in patient selection, lack of data surrounding the use of general anaesthesia, and prolonged time-to-treatment are potential contributors to negative results. The new generation of trials has the potential to address these pressing issues.

\section{References}

1 Lees KR, Bluhmki E, von Kummer R, Brott TG, Toni D, Grotta JC, Albers GW, Kaste M, Marler JR, Hamilton SA, Tilley BC, Davis SM, Donnan GA, Hacke W, ECASS, ATLANTIS, NINDS and EPITHET rt-PA Study Group, Allen K, Mau J, Meier D, del Zoppo G, De Silva DA, Butcher KS, Parsons MW, Barber PA, Levi C, Bladin C, Byrnes G: Time to treatment with intravenous alteplase and outcome in stroke: an updated pooled analysis of ECASS, ATLANTIS, NINDS, and EPITHET trials. Lancet 2010;375:1695-1703.

- 2 Frank B, Grotta JC, Alexandrov AV, Bluhmki E, Lyden P, Meretoja A, Mishra NK, Shuaib A, Wahlgren NG, Weimar C, Lees KR, VISTA Collaborators: Thrombolysis in stroke despite contraindications or warnings? Stroke 2013; 44:727-733.

3 Bhatia R, Hill MD, Shobha N, Menon B, Bal S, Kochar P, Watson T, Goyal M, Demchuk AM: Low rates of acute recanalisation with intravenous recombinant tissue plasminogen activator in ischaemic stroke: real world experience and a call for action. Stroke 2010;41; 2254-2258.

- 4 Rha JH, Saver JL: The impact of recanalization on ischemic stroke outcome: a meta-analysis. Stroke 2007;38: 967-973.

5 Broderick JP, Palesch YY, Demchuk AM, Yeatts SD, Khatri P, Hill MD, Jauch EC, Jovin TG, Yan B, Silver FL, von Kummer R, Molina CA, Demaerschalk BM, Budzik R, Clark WM, Zaidat O0, Malisch TW, Goyal M, Schonewille WJ, Mazighi M, Engelter ST, Anderson C, Spilker J, Carrozzella J, Ryckborst KJ, Janis LS, Martin RH, Foster LD, Tomsick TA, Interventional Management of Stroke (IMS) III Investigators: Endovascular therapy after intravenous t-PA versus t-PA alone for stroke. N Engl J Med 2013;368:893-903.

- 6 Ciccone A, Valvassori L, Nichelatti M, Sgoifo A, Ponzio M, Sterzi R, Boccardi E, SYNTHESIS Expansion Investigators: Endovascular treatment for acute ischemic stroke. N Engl J Med 2013;368:904-913.

7 Kidwell CS, Jahan R, Gornbein J, Alger JR, Nenov V, Ajani Z, Feng L, Meyer BC, Olson S, Schwamm LH, Yoo AJ, Marshall RS, Meyers PM, Yavagal DR, Wintermark M, Guzy J, Starkman S, Saver JL, MR RESCUE Investigators: A trial of imaging selection and endovascular treatment for ischemic stroke. N Engl J Med 2013;368:914-923.

8 Furlan A, Higashida R, Wechsler L, Gent M, Rowley H, Kase C, Pessin M, Ahuja A, Callahan F, Clark WM, Silver F, Rivera F: Intra-arterial prourokinase for acute ischaemic stroke. The PROACT II study: a randomized controlled trial. JAMA 1999;282:2003-2011.

9 Zaidat OO, Lazzaro M, McGinley E, Edgell RC, Nguyen T, Linfante I, Janjua N: Demand-supply of neurointerventionalists for endovascular ischemic stroke therapy. Neurology 2012;79(suppl 1):S35-S41.

10 Fiorella D, Hirsch JA, Woo HH, Rasmussen PA, Shazam Hussain M, Hui FK, Frei D, Meyers PM, Jabbour P, Gonzalez LF, Mocco J, Turk A, Turner RD, Arthur AS, Gupta R, Cloft HJ: Should neurointerventional fellowship training be suspended indefinitely? J Neurointerv Surg 2012;4:315-318.

11 Alberts MJ, Bertels C, Dawson DV: An analysis of time of presentation after stroke. JAMA 1990;263:65-68.

12 Saver JL, Smith EE, Fonarow GC, Reeves MJ, Zhao X, Olson DM, Schwamm LH, GWTG-Stroke Steering Committee and Investigators: The 'golden hour' and acute brain ischemia presenting features and lytic therapy in $>30,000$ patients arriving within 60 minutes of stroke onset. Stroke 2010;41:1431-1439. 
Maingard et al.: Future Directions for Intra-Arterial Therapy for Acute Ischaemic Stroke: Is There Life after Three Negative Randomized Controlled Studies?

13 Meretoja A, Weir L, Ugalde M, Yassi N, Yan B, Hand P, Truesdale M, Davis SM, Campbell BC: Helsinki model cut stroke thrombolysis delays to 25 minutes in Melbourne in only 4 months. Neurology 2013;81:1-6.

14 Meretoja A, Strbian D, Mustanoja S, Tatlisumak T, Lindsberg PJ, Kaste M: Reducing in-hospital delay to 20 minutes in stroke thrombolysis. Neurology 2012;79:306-313.

15 Jørgensen HS, Nakayama H, Kammersgaard LP, Raaschou HO, Olsen TS: Predicted impact of intravenous thrombolysis on prognosis of general population of stroke patients: simulation model. BMJ 1999;319:288289.

16 Hoffman J: Another trial is needed. BMJ 2000;320:1006.

17 Fagan SC, Morgenstern LB, Petitta A, Ward RE, Tilley BC, Marler JR, Levine SR, Broderick JP, Kwiatkowski TG, Frankel M, Brott TG, Walker MD: Cost-effectiveness of tissue plasminogen activator for acute ischemic stroke. NINDS rt-PA Stroke Study Group. Neurology 1998;50:883-890.

18 Tung CE, Win SS, Lansberg MG: Cost-effectiveness of tissue-type plasminogen activator in the 3- to 4.5-hour time window for acute ischemic stroke. Stroke 2011;42:2257-2262.

19 Tan Tanny SP, Busija L, Liew D, Teo S, Davis SM, Yan B: Cost-effectiveness of thrombolysis within 4.5 hours of acute ischemic stroke: experience from Australian stroke center. Stroke 2013;44:2269-2274.

20 Turk AS 3rd, Campbell JM, Spiotta A, Vargas J, Turner RD, Chaudry MI, Battenhouse H, Holmstedt CA, Jauch E: An investigation of the cost and benefit of mechanical thrombectomy for endovascular treatment of acute ischemic stroke. J Neurointerv Surg, E-pub ahead of print.

-21 Chen M: Cost-effectiveness of endovascular therapy for acute ischemic stroke. Neurology 2012;79(suppl 1):S16-S21.

22 http://clinicaltrials.gov/ct2/show/NCT01062698.

23 Saver JL, Jahan R, Levy EI, Jovin TG, Baxter B, Nogueira RG, Clark W, Budzik R, Zaidat O0, SWIFT Trialists: Solitaire flow restoration device versus the Merci retriever in patients with acute ischaemic stroke (SWIFT): a randomised, parallel-group, non-inferiority trial. Lancet 2012;380:1241-1249.

24 Almekhlafi MA, Menon BK, Freiheit EA, Demchuk AM, Goyal M: A meta-analysis of observational intra-arterial stroke therapy studies using the Merci device, Penumbra system, and retrievable stents. AJNR Am J Neuroradiol 2013;34:140-145.

25 Broderick JP, Palesch YY, Demchuk AM, et al: Endovascular therapy after intravenous t-PA versus t-PA alone for stroke. N Engl J Med 2013;368:893-903.

-26 von Kummer R, Allen KL, Holle R, Bozzao L, Bastianello S, Manelfe C, Bluhmki E, Ringleb P, Meier DH, Hacke W: Acute stroke: usefulness of early CT findings before thrombolytic therapy. Radiology 1997;205:327-333.

-27 Ciccone A, Valvassori L, Nichelatti M, et al: Endovascular treatment for acute ischemic stroke. N Engl J Med 2013;368:904-913.

-28 Lansberg MG, Thijs VN, Hamilton S, Schlaug G, Bammer R, Kemp S, Albers GW, DEFUSE Investigators: Evaluation of the clinical-diffusion and perfusion-diffusion mismatch models in DEFUSE. Stroke 2007;38:18261830.

29 Lansberg MG, Straka M, Kemp S, Mlynash M, Wechsler LR, Jovin TG, Wilder MJ, Lutsep HL, Czartoski TJ, Bernstein RA, Chang CW, Warach S, Fazekas F, Inoue M, Tipirneni A, Hamilton SA, Zaharchuk G, Marks MP, Bammer R, Albers GW, DEFUSE 2 Study Investigators: MRI profile and response to endovascular reperfusion after stroke (DEFUSE 2): a prospective cohort study. Lancet Neurol 2012;11:860-867.

-30 Gasparotti R, Grassi M, Mardighian D, Frigerio M, Pavia M, Liserre R, Magoni M, Mascaro L, Padovani A, Pezzini A: Perfusion CT in patients with acute ischemic stroke treated with intra-arterial thrombolysis: predictive value of infarct core size on clinical outcome. AJNR Am J Neuroradiol 2009;30:722-727.

-31 Tan ML, Mitchell P, Dowling R, Tacey M, Yan B: Shorter time to intervention improves recanalization success and clinical outcome post intra-arterial intervention for basilar artery thrombosis. J Clin Neurosci 2012;19: 1397-1400.

32 Tekle WG, Chaudhry SA, Hassan AE, Rodriguez GJ, Suri MF, Qureshi AI: Drip-and-ship thrombolytic treatment paradigm among acute ischemic stroke patients in the United States. Stroke 2012;43:1971-1974.

-33 Qureshi AI, Chaudhry SA, Rodriguez GJ, Suri MF, Lakshminarayan K, Ezzeddine MA: Outcome of the 'drip-andship’ paradigm among patients with acute ischemic stroke: results of a statewide study. Cerebrovasc Dis Extra 2012;2:1-8

34 Lyerly M, Albright K, Boehme A, Shahripour RB, Houston J, Rawal P, Kapoor N, Alvi M, Sisson A, Alexandrov A Alexandrov A: Potential biases in patients selected for drip and ship thrombolysis (meeting abstract). Neurology 2013;80:P04.053.

-35 Davis MJ, Menon BK, Baghirzada LB, Campos-Herrera CR, Goyal M, Hill MD, Archer DP, Calgary Stroke Program: Anesthetic management and outcome in patients during endovascular therapy for acute stroke. Anesthesiology 2012;116:396-405.

-36 John N, Mitchell P, Dowling R, Yan B: Is general anaesthesia preferable to conscious sedation in the treatment of acute ischaemic stroke with intra-arterial mechanical thrombectomy? A review of the literature. Neuroradiology 2013;55:93-100.

37 http://clinicaltrials.gov/show/NCT01492725.

38 http://clinicaltrials.gov/ct2/show/NCT01657461.

39 http://clinicaltrials.gov/show/NCT01429350.

40 http://clinicaltrials.gov/show/NCT01692379.

41 http://www.mrclean-trial.org/. 